\title{
A Petri net simulation model for virtual construction of earthmoving operations
}

\author{
F.F. Cheng ${ }^{\mathrm{a}, \mathrm{b}, *}$, Y.W. Wang ${ }^{\mathrm{b}}$, X.Z. Ling ${ }^{\mathrm{a}}, \mathrm{Y}$ Bai $^{\mathrm{c}}$ \\ a School of Civil Engineering, Harbin Institute of Technology, Harbin, China \\ b School of Management, Harbin Institute of Technology, Harbin, China \\ c Department of Civil, Environmental and Architectural Engineering, University of Kansas, USA
}

\section{A R T I C L E I N F O}

\section{Article history:}

Accepted 16 July 2010

Available online 6 November 2010

\section{Keywords:}

Earthmoving operation

Virtual construction

Simulation

Equipment allocation

Petri net

\begin{abstract}
A B S T R A C T
A common and extended Petri net simulation framework for virtual construction of earthmoving operations is developed to simulate dynamic changes of workflow and information flow in the earthmoving construction process and illustrate the constraint relationship between various operational equipment and construction restrictions. The proposed framework considers factors that influence earthmoving operations including randomness of construction activities, individual preference of equipment scheduling, and constraint relationship between equipment and construction environment. With the given equipment availability and project indirect cost, the framework can predict construction situation, equipment utilization rate, estimated duration and cost to achieve visualized and intelligent scheduling of virtual construction process in earthmoving operations. The simulation process is conducted on the CPNTools platform. The data required by the research were collected on-site in an actual case. The randomness of construction activities in earthmoving operations and main factors influencing construction are simulated. The sensitivity analysis for the model is carried out. The study will provide technical support and a management basis for equipment scheduling of earthmoving operations.
\end{abstract}

(c) 2010 Elsevier B.V. All rights reserved.

\section{Introduction}

Earthmoving operations refer to all the operations related to construction activities. It can be represented as a complex and dynamic discrete event which is affected by workflow, information flow, and other random factors.

The final goals for simulations of earthmoving operations are to improve productivity, equipment efficiency and construction safety. The optimal equipment configuration appropriate for construction projects is selected to improve the construction productivity and contractor benefits. This equipment configuration helps to optimize equipment efficiency, productivity, and minimize construction cost under any given condition. Based on the number of available equipment, characteristics and parameters of equipment, construction management principles, main factors and information about related cost, the simulation model of earthmoving operations is capable of predicting operation situations of earthmoving construction, equipment productivity, and the estimated completion time and cost. The model provides a reliable basis for organization and management for earthmoving operations.

\footnotetext{
* Corresponding author.

E-mail address: chengfeifei@hit.edu.cn (F.F. Cheng).
}

A considerable amount of simulation methods has been developed to predict performances related to parameters of earthmoving operations so as to achieve the previous stated goals. A queuing theory-based method is designed for construction operation simulation [6]. Halpin and Riggs [7] evaluated different fleet scenarios by Micro CYCLONE. Marzouk and Moselhi [13,14] optimized the earthmoving operations using an object-oriented simulation approach and Genetic Algorithm (GA). Hegazy and Kassab [8], Cheng and Feng [3] and Cheng et al. [4] proposed simulation-optimization by combining GA with CYCLONE or other simulation techniques. Van Tol and AbouRizk [19] proposed a resource allocation model for earthmoving operation. The model uses intelligent agents and belief networks to optimize the model performance. Dzeng and Lee [5] integrated simulation and a polyploidy GA to optimize development schedule. Zhang [20] presented a particle swarm optimization algorithm to search for the potential equipment-configurations. Zhang et al. [21] incorporated fuzzy set theory and DES method to resolve the fuzziness issues in the estimation of construction duration. Hola and Schabowicz [2] used an artificial neural network to predict the productivities of selected equipment that calculated the duration and cost of earthmoving operations. Kamat and Martinez [10,11] proposed visualization technology to describe the accurate, variablespeed motion of simulation objects visualizing modeled construction process and used 3D visualization to verify and validate discrete event construction simulation results. They [12] also implemented a virtual terrain-following algorithm and designed a computation scheme that 
correctly calculates and portrays the orientation of simulation objects. Prata et al. [17,18] suggested the Petri nets as a method for loader and truck teams dimensioning via simulation. Prata et al. [16] proposed a model using Stochastic Colored Petri Nets to represent the operational dynamics of earthmoving work.

Most simulation methods for earthmoving operations apply various intelligent algorithms to directly optimize the targets, such as resources, time and cost, while not considering the actual work flow changes of earthmoving operations. Little attention has been given to the random idling of equipment, intelligent scheduling for multifunction equipment operations, or the dynamics and random uncertainty for individual operating equipment during the operation process. This leads to the simulation results not reflecting the practical work objectively. The implementation of visualization on the simulation of earthmoving operations benefits the expression of dynamic change of workflow in construction activities. However, the expression capabilities of quantitative description of activity details and various complex constraint relationship are needed to be improved. Prata et al. [16] considered the operational dynamics of earthmoving work and selected local operations, which involves loading earth and truck hauling, as objects of simulation-optimization. The operational dynamics of earthmoving work by loader and truck teams was simulated. But the proposed Petri net model could not simulate the whole operation process and response to the typical random and dynamic events. Moreover, the model did not accurately simulate the dynamic change of workflow and information flow, constraint relationship between operational equipment and construction restrictions, and the intelligent schedule of equipment during the construction process.

To realize the virtual simulation for earthmoving operations processes, a common and extended Petri net model is proposed based on the analysis of earthmoving work flow and dynamic constraint relationships between construction equipment and construction activities. Compared to existing simulation models, the proposed model provides a clear description of the dynamic changes of work flow and information flow and the dynamic constraint relationship between various construction equipment and construction environment. The model simulates the randomness of construction activities and the main factors influencing construction. The CPNTools was used for the visualization of virtual simulation for earthmoving operations. The common construction factors and scheduling preferences for equipment in artificial intelligence are considered for the accurate simulation of the actual construction situation. Finally, this paper provides both practitioners and decision makers with an effective management approach for the selection of construction plans and multi-objective optimization.

\section{Overviews of earthmoving operations}

The core activities of earthmoving operations involve five works which are earthwork excavation, relocation within the construction site, load, haul and unload. Commonly, an earthmoving operation requires excavator, dozer, loader, and truck. In terms of operation characteristics, the construction equipment is classified as excavation and haulage units, loading units and haulage units.

Excavation and haulage units refer to the excavator cutting the quantities of soil and the dozer moving the loose soil to the loading location. If the construction place is big enough for the truck to enter, the relocation procedure for loose soil can be omitted and the soil cut by the excavator can be loaded directly. Loading units are responsible for moving earth by trucks and loading equipment. Normally, the loader completes the loading operations. Haulage units are in charge of delivering the soil to the designated locations by trucks. After unloading soil, the truck returns and continues the haulage process.

An excavator is a type of highly productive equipment dedicated to the operations of cutting and loading. Because its operational cost is higher than the loader, the excavator is less directly used for loading operations. However, when the quantity of material to be removed is considerable or when the time required to this removal is little, its utilization is a reasonable choice [16]. A dozer is equipped with a special blade and can be used for transferring and leveling the soil. It is appropriate for short haulage distances. A loader is capable of doing the operation work like loading, haulage and unloading with the characteristics of small loading capacity, low operational cost and high agility. It is used with a truck for loading the soil. A truck is the most usual transport tool for middle and long haulage distances.

In most earthmoving operations, contractors prefer using the existing or lower cost available equipment to complete the construction tasks within the limited duration and cost range disregarding the theoretically optimal equipment configuration. Under these circumstances, a simulation model is needed to predict the construction situation, the estimated completion time, the cost based on the given number of available equipment, equipment characteristics and parameters, main factors, and other relevant cost. The model provides a reliable basis for organization and management for earthmoving operations as a fast and cheap means.

The existing simulation methods for virtual construction earthmoving operations are concerned more about the final optimization results related to equipment, resources, time and cost. Little research has been carried out on change of workflow, dynamic operation and random uncertainties of individual equipment, simulation of local construction activities, quantitative analysis of the impact on construction activities by external environment, and intelligent equipment mobilization modeling in construction process. If the problems mentioned above cannot be solved, the constructed model and the simulation results obtained will have a large deviation from the real work.

\section{Simulation model of virtual construction for earthmoving operations}

\subsection{Workflow model for earthmoving operations}

According to the workflow of general earthmoving operations and constraint relationship between equipment and operational activities, an information model of construction operations was developed. Fig. 1 shows the main construction activities and constraint relationships in the model.

(1) Excavators operate in the excavation locations. The size of the working area determines the total number of equipment which works simultaneously. The excavated soil is temporarily placed near the working surface. Excavators have two functions: excavation and loading. The construction managers schedule equipment according to on-site operations to improve the productivity.

(2) The temporarily removed soil, which is placed around the working area, is transferred to a storage space in the soil loading location by dozers.

(3) Construction managers assign the excavators the loading location in order to assist loaders which run simultaneously in terms of the number of waiting trucks and the amount of soil to be loaded. The size of the loading area influences the maximum number of trucks loading simultaneously.

(4) Trucks completing the loading work are sent by construction managers to the unloading locations. After the loading work, trucks return to the temporary parking lot in the construction job-site waiting for another operation assignment. The efficiency of trucks is affected by road conditions and traffic. The effect of traffic conditions varies periodically according to the different times of the day. 


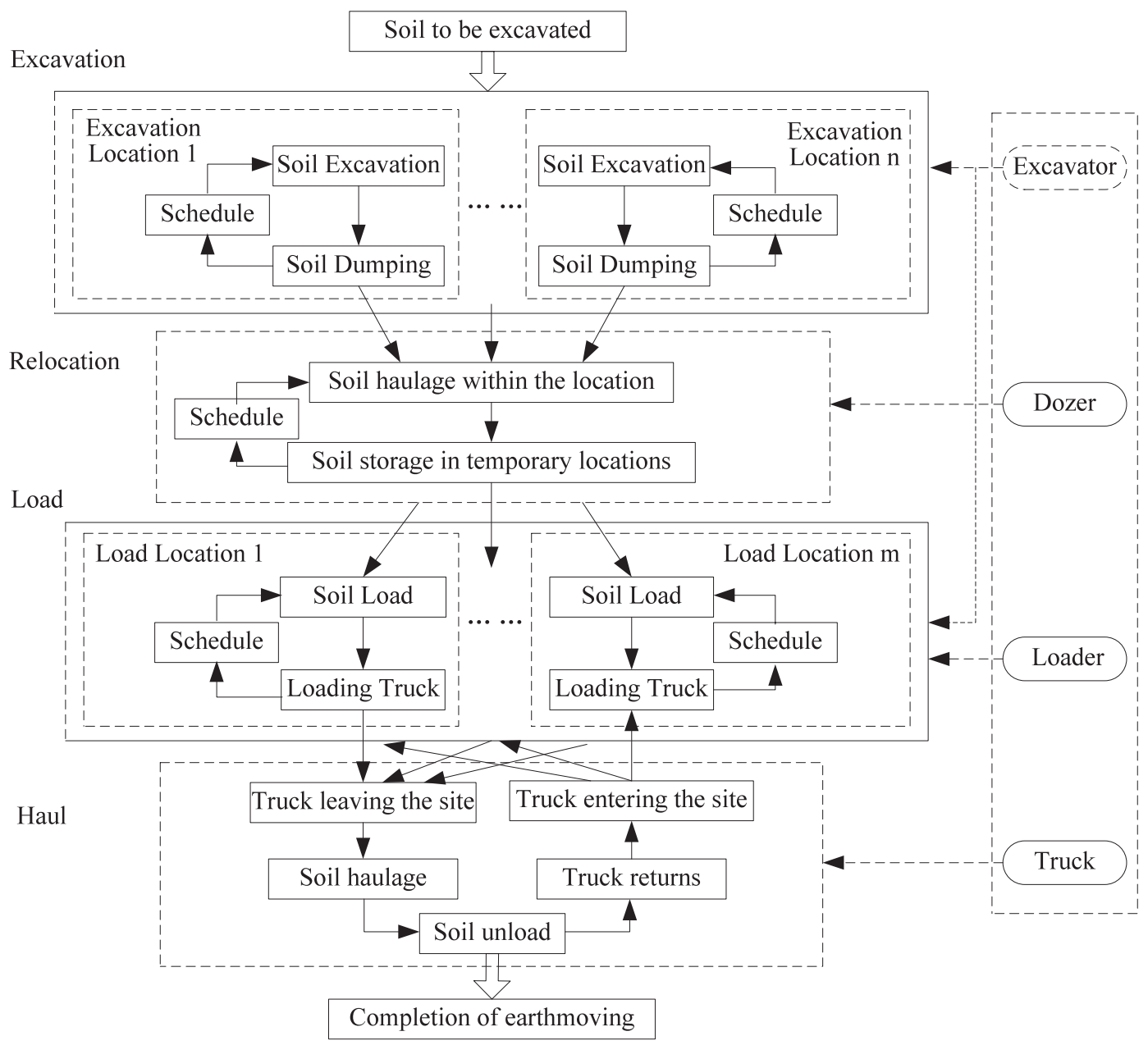

Fig. 1. Workflow model of earthmoving construction operations.

\subsection{CPN model for earthmoving operations}

The Petri net theory originates from the PhD thesis of Carl Adam Petri [15]. It provides a mathematical formalism and a graphical representation based on the graph theory in order to model the concurrent and asynchronous behavior of a discrete system. An ordinary Petri net consists of places, transitions and arcs. Each arc connects either a transition and a place or a place and a transition. The tokens reside on the places. For more information about the Petri net theory refer to Aalst [1].

The theory of Colored Petri Nets (CPN) was developed as an extension to the basic Petri nets theory [9]. In CPN, each token has attached a data value called the token color which can be investigated and modified by the occurring transition. With CPN, it is possible to use data types and complex data manipulation to make hierarchical descriptions. The detailed definition about CPN can be found in Jensen [9].

The CPN model of an earthmoving operation based on the Petri net theory is defined on the basis of a colored timed Petri net. The correctness of structure and operation for the model can be validated by liveness and safety of a Petri net. The formulism for the modes is expressed as follows:

CPN Simulation model of an earthmoving operation (CPNSMEO) is a 9-tuple:

CPNSMEO $=\left(R, P, T, F, M_{0}, C, G, I, S\right)$
Where:

(1) $R$ is a finite, non empty multi-set of types, denominated color set;

(2) $P$ is a finite set of places of dimension $n$;

(3) $T$ is a finite set of transitions of dimension $m$;

(4) $F$ is a finite set of arcs so that $P \cap T=P \cap F=T \cap F=\varnothing$;

(5) $M_{0}$ is an initiation status marking;

(6) $C$ is a color function, defined from $P$ on $R$;

(7) $G$ is a guard function;

(8) $I$ is an initiation function;

(9) $S$ is the firing possibility of transition $T$ when it conflicts with other transitions. $S=1$ when there is no conflict.

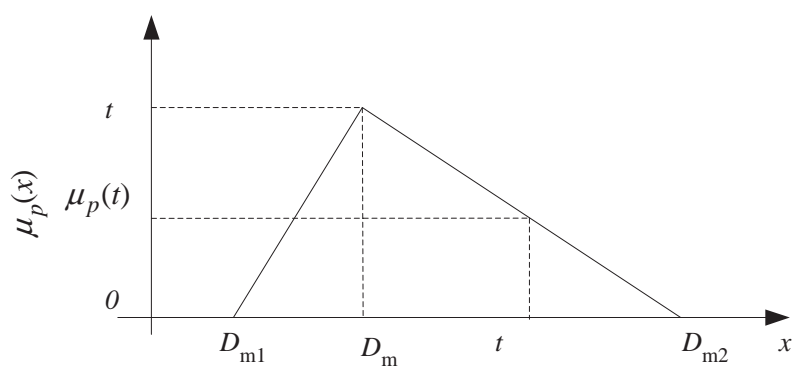

Fig. 2. Membership function of a triangular fuzzy set. 
Table 1

Basic parameters of equipment type and number.

\begin{tabular}{|c|c|c|c|c|}
\hline Bond strength model & Excavators & Dozers & Loaders & Trucks \\
\hline Type & WY160 & T3-100 & ZL20 & EXQ153 \\
\hline Volume of soil & $1.6 \mathrm{~m}^{3} /$ cycle & $100 \mathrm{~m} / \mathrm{min}$ & $\begin{array}{l}1.0 \mathrm{~m}^{3} / \\
\text { cycle }\end{array}$ & $13 \mathrm{~m}^{3}$ \\
\hline $\begin{array}{l}\text { Triangle function of } \\
\text { volume of soil }\end{array}$ & $(1.5,1.6,1.7)$ & $\begin{array}{l}(1.7,2.0 \\
2.2)\end{array}$ & $\begin{array}{l}(0.9,1.0 \\
1.1)\end{array}$ & See Table 2 \\
\hline $\begin{array}{l}\text { Triangle function } \\
\text { of time (min.) }\end{array}$ & $\begin{array}{l}\text { Excavation } \\
(1.4,1.6,1.7) \text {; } \\
\text { Load }(0.6,0.8,1.0)\end{array}$ & $\begin{array}{l}(0.9,1.0 \\
1.2)\end{array}$ & $\begin{array}{l}(0.5,0.6 \\
0.7)\end{array}$ & See Table 2 \\
\hline $\begin{array}{c}\text { No. of available } \\
\text { equipment }\end{array}$ & 14 & 16 & 7 & 40 \\
\hline Cost per Unit & $1200 \mathrm{RMB} / 8 \mathrm{~h}$ & $\begin{array}{l}600 \mathrm{RMB} / \\
8 \mathrm{~h}\end{array}$ & $\begin{array}{l}800 \mathrm{RMB} / \\
8 \mathrm{~h}\end{array}$ & $\begin{array}{l}300 \mathrm{RMB} / \\
\text { Unit }\end{array}$ \\
\hline
\end{tabular}

Table 2

Triangle probability function of trucks operation time (min).

\begin{tabular}{llll}
\hline & Haul & Dump & Return \\
\hline 10 p.m.-6 a.m. & $(13.0,14.5,15.0)$ & $(1.1,1.2,1.4)$ & $(10.5,11.5,12.0)$ \\
6 a.m.-10 p.m. & $(18.0,20.5,21)$ & $(1.1,1.2,1.4)$ & $(17.0,18.0,20.0)$ \\
\hline
\end{tabular}

CPNSMEO is different from the general colored Petri net. The token colors in CPNSMEO are determined by execution environment and influenced by other token colors.

\section{Application of the model}

\subsection{Application case and data collection}

In this study, a case of a Zijin City high-rise residential project located in Harbin, China was selected as a targeted construction operation. Data were collected through site observations and interviews with project managers and site engineers. The building area is a total of $320,000 \mathrm{~m}^{2}$. The operations involve excavating soil of $180,000 \mathrm{~m}^{3}$ on the job-site and moving soil to the placement located at a distance of approximately $15 \mathrm{~km}$ from the job-site. The average density and loose density of soil are $1.53 \mathrm{t} / \mathrm{m}^{3}$ and $1.2 \mathrm{t} / \mathrm{m}^{3}$, respectively. The equipment team is composed of excavators, dozers, loaders and trucks.

Limited by the size of the job-site, the excavation area can be set up to a maximum of 8 excavation locations. Each excavation location accommodates a maximum of two excavators working at the same time. The loading area can be set up to a maximum of 5 loading locations. Each loading location can allow up to two loaders to load a truck simultaneously. There is a temporary soil storage space with a maximum capacity of $2000 \mathrm{~m}^{3}$ in the excavation area. In addition, because the construction site is located in the city, the haulage of trucks for earthmoving is restricted by traffic. The traffic has a great impact on truck transportation between 6 a.m. and 10 p.m. The impact is relatively small during other times.

A large number of unpredictable events occur during the construction process of earthmoving operations. The main uncertainty is the diversities of working hours for excavators, dozers, loaders and trucks each time and the loading capacity of soil. In this study, the fuzzy triangular probability function was used to simulate the uncertainties in construction activities. A triangular fuzzy set is denoted by $\left(D_{\mathrm{m} 1}, D_{\mathrm{m}}, D_{\mathrm{m} 2}\right) . D_{\mathrm{m} 1}$ is the minimum. $D_{\mathrm{m}}$ is the most possible value. $D_{\mathrm{m} 2}$ is the maximum. The membership functions can be illustrated by Fig. 2 .

The construction equipment was randomly sampled at different time periods for construction activity observations. The total of observation is over 100 times for each earthmoving operation. One hundred statistical samples of observation data on job-site for each activity were selected. The data were processed by Latin hypercube sampling. The assumed probability distribution function was verified through 50 randomly selected observation data. None of the verifications deny the assumption which shows that the collected data fit the fuzzy triangular probability function. Tables 1 and 2 show the detailed descriptions of the construction job-site and observation statistical data, respectively.

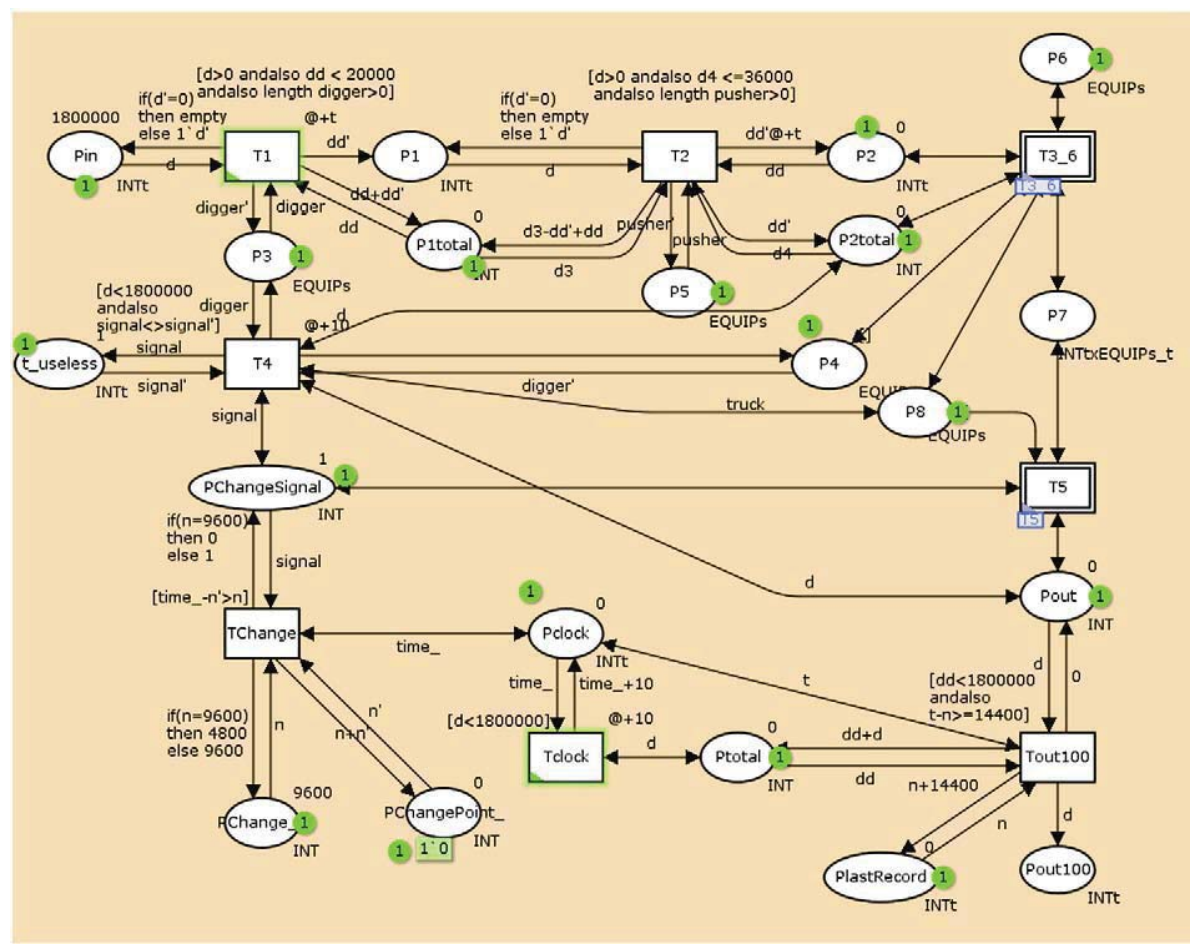

Fig. 3. Colored timed Petri net model of earthmoving operations. 
Table 3

Definitions of the main transitions and places of the model

\begin{tabular}{ll}
\hline Transitions & Places \\
\hline T1: soil excavation & Pin: soil to be excavated \\
T2: soil moving on construction site & P1: soil for temporary storage \\
T3: loader's loading & P2: soil to be loaded \\
T4: Scheduling module & P3: excavator ready to maneuver \\
T5: haul simulation module & P4: excavator for loading \\
T3_6: load simulation module & P5: dozer ready to maneuver \\
T6: excavator's loading & P6: loader ready to maneuver \\
T51: hauling module & P7:truck with load ready for departure \\
T52: hauling module & P8: truck ready to load \\
T53: hauling module & P51: hauling module \\
T54: hauling module & P52: hauling module \\
& P53: hauling module \\
& Pout: soil in dumping area \\
\hline
\end{tabular}

4.2. Simulation implementation of virtual construction model for earthmoving operations

The CPNSMEO mode was implemented utilizing the software CPNTools developed by Aarhus University. This software is used for model, simulation and analysis of a colored Petri net. The visual interface is easy for users to operate to achieve the simulation.

Fig. 3 shows the visualization simulation of CPNSMEO by CPNTools.

The present Table 3 introduces the captions of the places and the transitions of the proposed model. Other transitions and places that cannot be noted in Table 3 are auxiliary parts for model control and establishment. The data used for simulation are the statistics data in Tables 1 and 2, respectively.

The soil in place Pin is excavated at transition $T 1$ and stored temporarily in place $P 1$. The soil is moved at $T 2$ to place $P 2$ and ready for loading. The soil in place $P 2$ is loaded to place $P 8$ through the subnet T3_6 of the loading simulation module. After the operation in transition subnet $T 5$ of the haul simulation module, the soil is moved to the dumping area. The empty truck returns. The process forms a cycle.

Construction managers optimize and control the construction equipment and resources according to the job-site situation in practical earthmoving operations. The control mechanism of the T4 module in CPNSMEO is the following:

(1) The model monitors the volume of soil in $P 1$ and $P 2$, as well as the real time every minute. The monitoring results feed back to the T4 module.

(2) If the volume of soil in P1 is up to the maximum storage volume of $2000 \mathrm{~m}^{3}$, excavators stop work. If the volume of soil in $P 2$ is up to the maximum storage volume of $3600 \mathrm{~m}^{3}$, dozers stop work.

(3) When the truck capacity increases between 10 p.m. and 6 a.m. and the soil volume of temporary storage in place $P 2$ is more than $3000 \mathrm{~m}^{3}$, the model automatically transfers some of the excavators to the loading area. When the truck capacity declines between 6 a.m. and 10 p.m., and the soil volume of temporary storage in place $P 1$ is less than $3000 \mathrm{~m}^{3}$, the model automatically transfers some of the excavators back to the excavation area.

CPNSMEO carries out the scheduling task on the job-site through the T4 module and related functions.

The model accounts for the volume of soil in the loading process, traffic factors for truck haulage, time-consumption for excavator mobilization, and different productivities of excavation and load for excavators. Other factors influencing the construction activities are expressed, including maximum numbers of trucks in loading locations and waiting locations, and the maximum number of loading trucks. The simulation process is completed on the CPNTools platform.

Fig. 4. shows the simulation of trucks loading process in the T3_6 loading module.

This paper in the T3_6 simulation module, T3, T6 and T3_6 are defined as three possible working patterns: individual work of loaders, individual work of excavators and collaboration of loaders and excavators. Place P2total passes the volume of soil to be loaded to T4 of the equipment dispatch module. T4 controls the three loading patterns of T3, T6 and T3_6 according to the control mechanisms for job-site equipment scheduling. Transitions T3, T6 and T3_6 operate trucks loading in place $P 8$. The truck tokens in place $P 8$ pass the volume of soil to the guard function of corresponding transitions in real time. The guard function determines the next working activity in terms of volume of trucks. The loading volume of trucks is a random

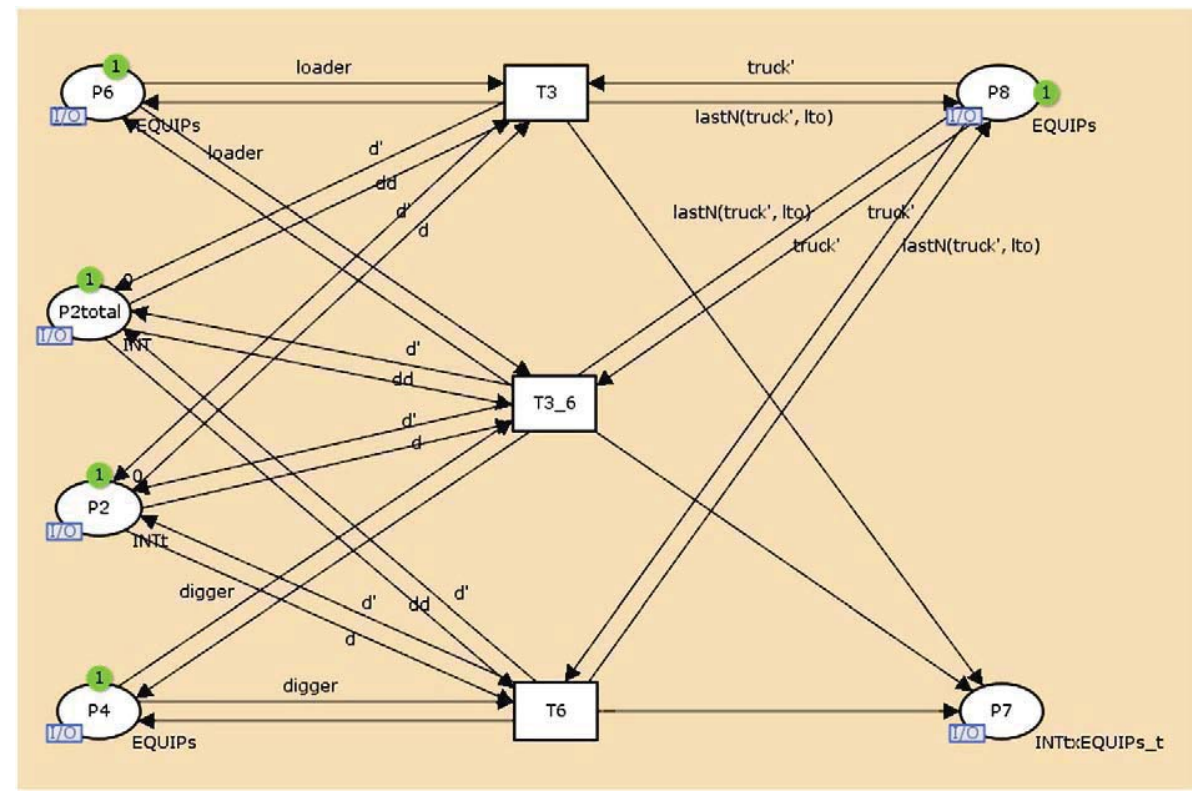

Fig. 4. T3_6 soil loading sub layer of CPNSMEO. 
Table 4

Summary of the scenarios of earth moving.

\begin{tabular}{|c|c|c|c|c|c|c|}
\hline Scenario & $\begin{array}{l}\text { Number of } \\
\text { excavators }\end{array}$ & $\begin{array}{l}\text { Number } \\
\text { of dozers }\end{array}$ & $\begin{array}{l}\text { Number } \\
\text { of loaders }\end{array}$ & $\begin{array}{l}\text { Number } \\
\text { of trucks }\end{array}$ & $\begin{array}{l}\text { Working } \\
\text { time (day) }\end{array}$ & $\begin{array}{l}\text { Scenario } \\
\text { cost (RMB) }\end{array}$ \\
\hline 1 & 8 & 4 & 5 & 40 & 21 & 6304200 \\
\hline 2 & 10 & 4 & 5 & 40 & 19 & 6345000 \\
\hline 3 & 12 & 4 & 5 & 40 & 20 & 6544200 \\
\hline 4 & 14 & 4 & 5 & 40 & 18 & 6549000 \\
\hline 5 & 8 & 4 & 6 & 40 & 21 & 6354600 \\
\hline 6 & 10 & 4 & 6 & 40 & 21 & 6506800 \\
\hline 7 & 12 & 4 & 6 & 40 & 20 & 6592200 \\
\hline 8 & 14 & 4 & 6 & 40 & 18 & 6473400 \\
\hline 9 & 8 & 5 & 5 & 40 & 18 & 6192600 \\
\hline 10 & 10 & 5 & 5 & 40 & 16 & 6208200 \\
\hline 11 & 12 & 5 & 5 & 40 & 15 & 6259200 \\
\hline 12 & 14 & 5 & 5 & 40 & 15 & 6367200 \\
\hline 13 & 8 & 5 & 6 & 40 & 16 & 6131400 \\
\hline 14 & 10 & 5 & 6 & 40 & 16 & 6246600 \\
\hline 15 & 12 & 5 & 6 & 40 & 16 & 6361800 \\
\hline 16 & 14 & 5 & 6 & 40 & 16 & 6477000 \\
\hline 17 & 8 & 5 & 7 & 40 & 17 & 6224400 \\
\hline 18 & 10 & 5 & 7 & 40 & 17 & 6346800 \\
\hline 19 & 12 & 5 & 7 & 40 & 16 & 6400200 \\
\hline 20 & 14 & 5 & 7 & 40 & 16 & 6515400 \\
\hline 21 & 8 & 6 & 6 & 40 & 15 & 6106200 \\
\hline 22 & 10 & 6 & 6 & 40 & 15 & 6214200 \\
\hline 23 & 12 & 6 & 6 & 40 & 15 & 6322200 \\
\hline 24 & 14 & 6 & 6 & 40 & 13 & 6279000 \\
\hline 25 & 8 & 6 & 7 & 40 & 16 & 6198600 \\
\hline 26 & 10 & 6 & 7 & 40 & 14 & 6186600 \\
\hline 27 & 12 & 6 & 7 & 40 & 14 & 6287400 \\
\hline 28 & 14 & 6 & 7 & 40 & 13 & 6310200 \\
\hline
\end{tabular}

variable in a certain range. If the accumulated volume of soil exceeds the total capacity of trucks after the last loading is completed, the model will put the extra soil aside to be loaded.

\subsection{Results analysis}

Table 4 shows the 28 equipment configuration plans which are the simulation results made by traditional equipment configuration management methods under the conditions of actual equipment. The accuracy of the model simulation time is set to $0.1 \mathrm{~min}$. The accuracy of soil volume simulation is set to $0.1 \mathrm{~m}^{3}$. The model was used in all the 28 scenarios for simulation analysis. The results are shown in Table 4 and Fig. 4, respectively.

Fig. 5 shows the output of the simulation results. The horizontal axis stands for operation time (Unit: Days). The vertical axis stands for operation cost (Unit: RMB).

It can be seen from Fig. 5 that three scenarios which have minimum duration, minimum cost and both minimum duration and cost are scenarios 28, 21 and 26, respectively. Since the simulation
Table 5

Equipment configurations for different optimization goals.

\begin{tabular}{|c|c|c|c|c|c|c|}
\hline \multirow[t]{2}{*}{ Optimization } & \multirow{2}{*}{$\frac{\text { Excavator }}{\text { WY160 }}$} & \multirow{2}{*}{$\frac{\text { Dozer }}{\text { T3-100 }}$} & \multirow{2}{*}{$\frac{\text { Loader }}{\text { ZL20 }}$} & \multirow{2}{*}{$\begin{array}{l}\text { Truck } \\
\text { EXQ153 }\end{array}$} & \multirow[t]{2}{*}{$\begin{array}{l}\text { Time } \\
\text { (day) }\end{array}$} & \multirow[t]{2}{*}{$\begin{array}{l}\text { Cost } \\
\text { (RMB) }\end{array}$} \\
\hline & & & & & & \\
\hline Minimized time & 14 & 6 & 7 & 40 & 13 & 6310200 \\
\hline Minimized cost & 7 & 6 & 6 & 40 & 15 & 6052200 \\
\hline Minimized time and cost & 10 & 6 & 7 & 40 & 14 & 6186600 \\
\hline
\end{tabular}

scenarios in which the number of excavators is odd are omitted, the equipment configurations that need to be analyzed are those in which the number of excavators is odd and near the scenarios 28, 21 and 26. Table 5 shows the equipment configurations for different optimization goals.

Based on the equipment configuration in scenario 28, the amount of the fourth equipment is changed individually, while the numbers of the other three types of equipment remain constant. Fig. 6 shows the simulation analysis results of each of the new configurations.

The cost of trucks is a constant value which depends on the total number of trucks haulage in actual construction. When few trucks are idle, the number of trucks does not affect the rent cost of whole construction equipment. It can be seen that the critical value of the number of trucks is 30 in Fig. 6(d). In the actual case study, there are 40 trucks on the job-site, which ensures the normal productivity of other sectors of the construction.

It can be noticed in Fig. 6 that the number of excavators has a continuously increasing impact on the productivity of earthmoving operations. The increase of numbers of dozers and loaders can also improve the productivity of operations. However, the increase of numbers of equipment cannot improve the productivity when the number of dozers is over 6 and the number of excavators is over 7 . From the above, the key processes for the whole earthmoving operations are soil movement on the jobsite and soil load. The impact caused by changes in numbers of dozers and loaders on productivity of earthmoving operations is more than the impact caused by changes in numbers of excavators and trucks.

\subsection{Model validation}

The equipment configuration of earthmoving operations for the Zijin City high-rise residential project in Harbin, China is 13 excavators, 6 dozers, and 7 loaders. The total of accumulated working days is 15. Fifty simulations were conducted by using the corresponding configurations. The simulation result for the duration is 13.82 days. The simulation deviation for the duration is $7.86 \%$. The deviation for the cost is $4.32 \%$. The duration calculated by the deterministic model is 13 days. Compared to that, the result given by

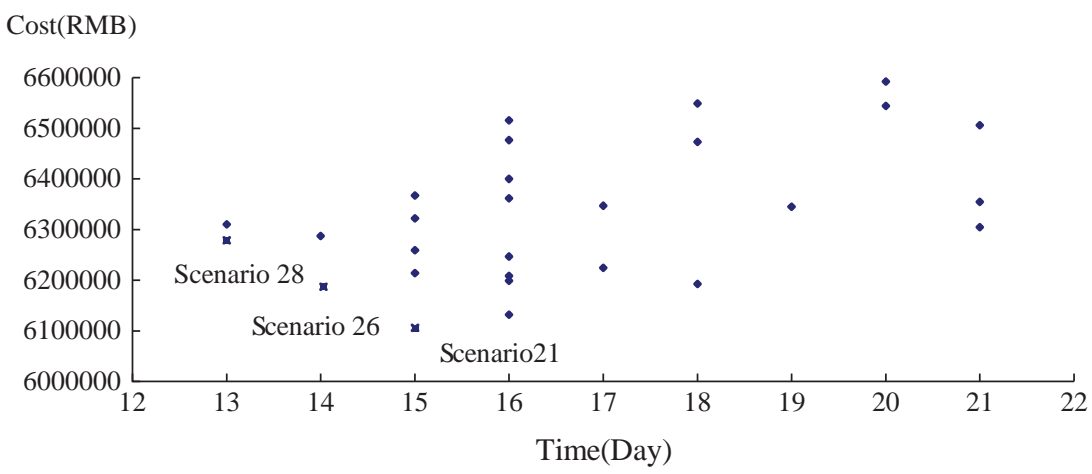

Fig. 5. Optimization output for the application example. 


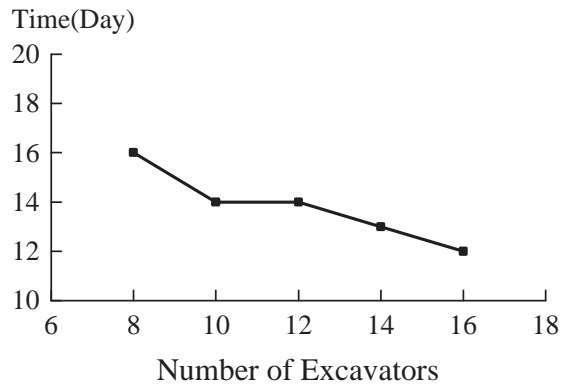

(a) Excavator

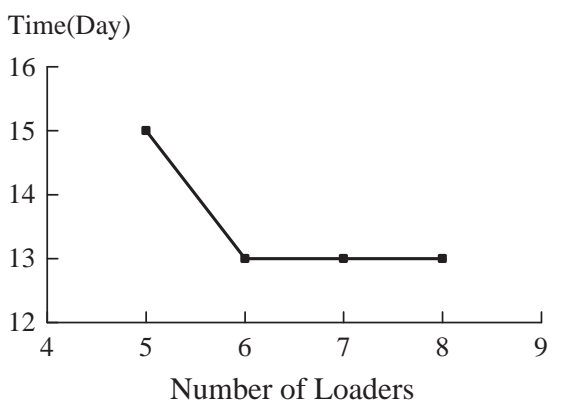

(c) Loader
Time(Day)

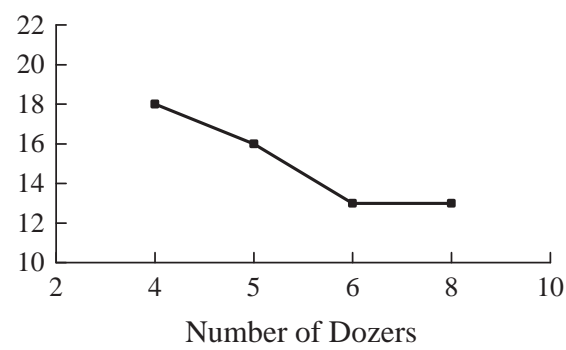

(b) Dozer

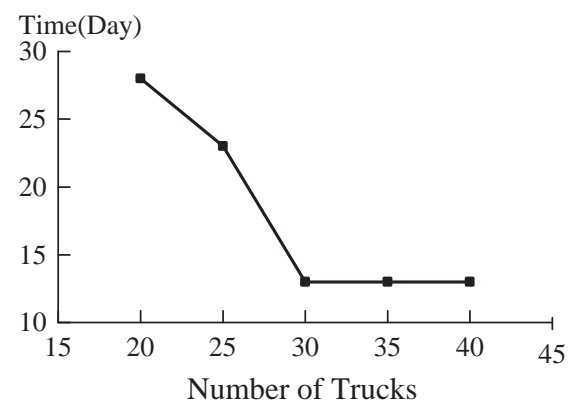

(d) Truck

Fig. 6. Effects of different amounts of equipment on the productivity of earthmoving operations.

the simulation model is more accurate by 5.47\%. Through the interviews with site engineers and managers, the verifications were carried out for the activity operation processes and set parameters in the simulation. The deviation was determined by three factors:

(1) $80 \%$ of the observation data is collected in the day time. Although workers switch every $8 \mathrm{~h}$, their productivities are higher compared to the workers who work at night. Therefore, the simulation parameters are higher than the actual values.

(2) The earthmoving operations in the case were interrupted twice due to the rain. The equipment productivities at the time they resumed were lower than the statistic data in a short time period, which results in the extension of the actual duration.

(3) The routine maintenance for the equipment is needed in actual operations, such as refueling or regular checks for the parts, which is not reflected in the simulation model. That also results in the extension of the duration.

\section{Conclusion}

This study proposed a general and extended Petri net model for virtual construction of earthmoving operations. The model supports the dynamics and visualization of simulation under complex construction conditions with multiple constraints. Compared to other simulation models for earthmoving construction, the advantages of this model can be summarized as the following. First, the model provides an accurate expression of changes in workflow and information flow in construction processes, as well as the constraint relationships between various equipment and construction restrictions. Second, the proposed model achieves the visualization of dynamic simulation for the randomness of construction activities and factors influencing construction. It more closely simulates the actual scenarios. The simulation results show a high degree of consistency with the actual results. Third, the model simulates intelligent scheduling for the equipment with different productivities in the same construction process. Finally, the powerful extensibility of the model helps its application to other types of earthmoving construction objects with the modification of transitions, tokens or guard functions.

However, this study has limitations. For example, in order to improve the accuracy of simulation, additional raw data should be collected and processed, which is a time-consuming process. The optimization capability for the equipment configurations which involves multiple types of resources and a large amount of available equipment should be improved. Further study should focus on modeling of earthmoving construction in complex environments and optimizing combinations of multiple types of equipment.

\section{Acknowledgements}

This research was supported by the "11th-Five-Year Plan" National Key Technologies R\&D Program of China (No. 2006BAJ03A10) and the Postdoctoral Foundation of Harbin Institute of Technology.

\section{References}

[1] W.M.P. Aalst, "The application of Petri-nets to workflow management", Journal of Circuits, Systems and Computers 8 (1) (1998) 21-66.

[2] Bozena Hola, Krzysztof Schabowicz, Estimation of earthworks execution time cost by means of artificial neural networks, Automation in Construction 19 (5) (2010) 570-579.

[3] T.M. Cheng, C.W. Feng, An effective simulation mechanism for construction operations, Automation in Construction 12 (3) (2003) 227-244.

[4] T.M. Cheng, C.W. Feng, Y.L. Chen, A hybrid mechanism for optimizing construction simulation models, Automation in Construction 14 (1) (2005) 85-98.

[5] Dzeng Ren-Jye, Lee Hsin-Yun, Optimizing the development schedule of resort projects by integrating simulation and genetic algorithm, International Journal of Project Management 25 (5) (2007) 506-516.

[6] W. Halpin, W. Woodhead, Design of Construction and Process Operations, John Wiley \& Sons, Inc., New York, 1976.

[7] D. Halpin, S. Riggs, Planning and Analysis of Construction Operations, John Wiley \& Sons, Inc., New York, 1992.

[8] T. Hegazy, M. Kassab, Resource optimization using combined simulation and genetic algorithms, Journal of Construction Engineering and Management, ASCE 129 (6) (2003) 698-705.

[9] K. Jensen, Coloured Petri Nets: Basic Concepts, Analysis Methods and Practical Use Volume 2: Basic Concepts, Springler-Verlag, 1997. 
[10] V.R. Kamat, J.C. Martinez, Variable-speed resource motion in animations of discreteevent process models, Systems Analysis Modelling Simulation 43 (4) (2003) 455-467.

[11] V.R. Kamat, J.C. Martinez, Validating complex construction simulation models using 3D visualization, in: S. Chick, P.J. Sánchez, D. Ferrin, D.J. Morrice (Eds.), Proceedings of the 2003 Winter Simulation Conference, New Orleans, L.A, IEEE, Piscataway, N.J, 2003, pp. 1518-1526.

[12] V.R. Kamat, J.C. Martinez, Generic representation of 3D motion paths in dynamic animations of simulated construction processes, Automation in Construction 17 (2) (2008) 188-200.

[13] M. Marzouk, O. Moselhi, Optimizing earthmoving operations using object-oriented simulation, in: J.A. Joines, R.R. Barton, P. Fishwick, K. Kang (Eds.), Proceedings of the 2000 Winter Simulation Conference, Orlando, Fla, IEEE, Piscataway, N.J, 2000, pp. 1926-1932.

[14] M. Marzouk, O. Moselhi, Multiobjective optimization of earthmoving operations, Journal of Construction Engineering and Management, ASCE 130 (1) (2004) 105-113.

[15] C.A. Petri, Kommunikation mit Automaten, Schriften des Instituts für Instrumentelle Mathematik der Universität Bonn, Bonn, Germany v. d, 1962.
[16] B.A. Prata, E.F. Nobre Júnior, G.C. Barroso, A stochastic colored petri net model to allocate equipments for earth moving operations, Journal of Information Technology in Construction 13 (2008) 476-490.

[17] B.A. Prata, E.F. Nobre Júnior, G.C. Barroso, Modelagem de sistemas de terraplenagem: uma apli-cação das redes de Petri, XVI Iberian Latin American Congress on Computational Methods in Engineering, Guarapari, 2005.

[18] B.A. Prata, E.F. Nobre Júnior, G.C. Barroso, Dimensionamento de equipes mecânicas em obras de terraplenagem usando redes de Petri coloridas, XXXIX Simpósio Brasileiro de Pesquisa Operacional, Fortaleza, Brasil, 2007.

[19] A.A. Van Tol, S.M. AbouRizk, Simulation modeling decision support through belief networks, Simulation Modelling Practice and Theory 14 (5) (2006) 614-640.

[20] H. Zhang, Multi-objective simulation-optimization for earthmoving operations, Automation in Construction 18 (1) (2008) 79-86.

[21] H. Zhang, Heng Li, C.M. Tam, Fuzzy discrete-event simulation for modeling uncertain activity duration, Engineering, Construction and Architectural Management 11 (6) (2004) 426-437. 